\title{
Deforestation reduces the genetic structure of an epiphytic weed across space and time: an IBM approach
}

\section{Cleber Juliano Neves Chaves ${ }^{1,2^{*}}$, Bárbara Simões Santos Leal ${ }^{1,2}$, Davi Rodrigo Rossatto ${ }^{3}$, Uta Berger $^{4}$, Clarisse Palma-Silva ${ }^{2}$}

${ }^{1}$ Programa de Pós-graduação em Ecologia e Biodiversidade, Universidade Estadual Paulista, Instituto de Biociências, 13506-900 Rio Claro, Brazil

${ }^{2}$ Departamento de Biologia Vegetal, Instituto de Biologia, Universidade Estadual de Campinas, 13083-862 Campinas, Brazil

${ }^{3}$ Departamento de Biologia, Universidade Estadual Paulista, 14884-900 Jaboticabal, Brazil

${ }^{4}$ Institute of Forest Growth and Computer Sciences, Technische Universität Dresden, 01737

Tharandt, Germany

\section{* Correspondence:}

Dr. Cleber Chaves

cleberchaves@gmail.com

Keywords: Agent-based model, cloning, fine-scale genetic structure, forest loss, Individualbased model, invasive species, selfing, weeds 


\section{Abstract}

Deforestation has allowed the massive dispersal and reproduction of some plants that are commonly referred to as weeds. The rapid spread of many weeds into newly disturbed landscapes is often boosted by clonal growth and self-fertilization strategies, which conversely increases the spatial genetic structure (SGS) of populations and reduces the genetic diversity. Here, we use empirical and modeling approaches to evaluate the spatio-temporal SGS dynamics of Tillandsia recurvata (L.) L., a common epiphytic weed with selfing reproduction and clonal growth widespread in dry forests and anthropically deforested landscapes in North and South America. We constructed an individual-based model (IBM) and adjusted the parameters according to empirical genetic data, to simulate the spreading of $T$. recurvata over time and across random landscapes with distinct tree densities. From empirical data, we observed a strong SGS among $T$. recurvata subpopulations hosted on neighbor trees and a contemporary spread from several population sources. Our model shows that the highest SGS appear in landscapes with more than 200 trees/ha and up to the $5^{\text {th }}$ year of colonization of open landscapes (ca. 100 trees/ha) when SGS starts to reduce drastically. These results suggest that the deforestation commonly observed in anthropically transformed landscapes may reduce the dispersal limitation and genetic structure of T. recurvata subpopulations, creating suitable conditions for the rapid spread of T. recurvata from multiple surrounding sources. The combination of clonal growth and self-fertilization with the optimal conditions created by anthropogenic transformations may explain the spreading success of $T$. recurvata and other weeds into new landscapes. Our results indicate that the drastic reductions in tree densities induced by human-modifications in natural landscapes may lead to a partial loss of resistance for dispersal by wind and increased the conditions for T. recurvata to develop massive populations in anthropogenic landscapes. 


\section{INTRODUCTION}

Intensive disturbances are inherent to human history and have substantial effects on natural communities (de Wet and Harlan 1975). Ecosystems are currently subjected to unprecedented rates of human-induced changes that are fostering the sixth mass extinction (Ceballos et al. 2015). However, not all organisms respond the same way to human disturbances. While many species become extinct or migrate, others thrive in anthropogenic environments and can spread into natural environments (Wilcove 1985; Airoldi and Bulleri 2011). Indeed, human activities, such as those related to deforestation, have allowed the dispersal and reproduction of many species, such as those commonly referred to as weeds (Airoldi \& Bulleri 2011). Weeds are opportunistic species that can evolve from introduced or native species that grow within humantransformed landscapes without being cultivated and negatively affecting both the environment and the economy (Baker 1974; de Wet and Harlan 1975; Richardson et al. 2008).

Between 50 and $80 \%$ of all invasive plant species can be classified as weeds, depending on current impacts and human perception (Richardson et al. 2008). However, native species possessing traits that pre-adapt them to establish in newly disturbed areas can also evolve into weeds (van Etten et al. 2017). In addition to landscape disturbances, propagule pressure, and individual density, the spreading rate of weeds is mainly driven by their high dispersal abilities and wide plasticity, which enable them to rapidly colonize large areas (Baker 1974; Booth et al. 2002; Kuester et al. 2014; van Kleunen et al. 2018; De Bona et al. 2019). In particular, clonal growth and self-fertilization (hereafter referred to as 'selfing') are some of the most important adaptations that allow weeds to establish new populations after long-distance dispersal events (Baker 1955; Razanajatovo et al. 2016). Despite their entirely different origins, both clonal and selfing abilities help increase the invasiveness of a species by mitigating the Allee effect of small populations and, therefore, enhance reproductive assurance and genetic transmission (VallejoMarín et al. 2010; Rodger et al. 2013; Barrett and Harder 2017). While selfing can increase species' investment in seed production, clonal growth speeds up ramet production and reduces the likelihood of genet death by sharing stochastic risk over multiple ramets (Klimeš et al. 1997; Barrett 2015).

Despite the positive effect of cloning and selfing strategies on weed invasiveness, the aggregation of self-fertilized offspring and clonal individuals strongly influences the spatial genetic structure (SGS) of populations, reducing local genetic diversity and promoting inbreeding depression (Heywood 1991; Barrett 2013; Barrett et al. 2014; Barrett 2015). In turn, clonal growth may lead to the maintenance of (once established) genetic diversity (Ellstrand and Roose 1987; Loh et al. 2015), while continuous selfing can result in the absence of inbreeding 
depression as a consequence of purging of deleterious alleles over generations (Hedrick 1994; Arunkumar et al. 2015; Barrett and Harder 2017). These effects lead to a strong population subdivision, creating a metapopulation dynamic with extinction in a site being balanced by recolonizations. This dynamic selects selfing and clonal genotypes, due to their higher capacities of recolonization (Pannell and Barrett 1998; Barrett 2013).

Understanding local spread dynamics of weeds is essential to elucidate how native selfing and clonal species opportunistically reach broad range distributions, despite their tendency to form highly aggregated populations with low genetic diversity. Aside from the aggregation tendency of selfing and clonal species, individuals within populations with reduced abundance and limited seed dispersal usually are highly related at the beginning of colonization (Hamrick and Trapnell 2011). With an increase in abundance after colonization, the kinship among individuals often reduces due to greater overlapping of maternal seed shadows and successive introductions of new genotypes through seed dispersal from neighbor populations (Hamrick and Trapnell 2011; Côrtes et al. 2013). Therefore, density-relatedness dynamics is expected to reduce the high SGS expected for populations of selfing and clonal species throughout colonization stages (Hamrick and Trapnell 2011; Trapnell et al. 2013; Chung et al. 2018).

Aside from the intrinsic effects of clonal growth and self-fertilization, the deforestation seems to be a turning point in which some natural species develop fast colonization abilities and form abundant populations into newly disturbed landscapes (Cardelús et al. 2005; Roberts et al. 2005; Quaresma et al. 2018). To shed light on this topic, here we integrate empirical and simulated genetic data to study the spatio-temporal dynamics of the local spread of Tillandsia recurvata (L.) L., an epiphytic weed with selfing and clonal growth strategies widespread in canopies of human-modified landscapes in the American continent (e.g. Claver et al. 1983; Bartoli et al. 1993; Flores-Palacios et al. 2015a). Specifically, we aimed (I) to investigate whether subpopulations of $T$. recurvata growing on neighbor trees of an anthropical landscape are genetically structured; (II) to examine the temporal dynamics of genetic structuring of $T$. recurvata subpopulations in an anthropical landscape; as well as (III) to examine whether the genetic structuring of $T$. recurvata varies according to tree densities in each landscape. Since obtaining continuous empirical genetic data over a long period can often be unfeasible (Epps and Keyghobadi 2015), modeling approaches are helpful to understand spatio-temporal effects on the genetic structure. Individual-based models (IBMs) explicitly incorporate characteristics of individuals (e.g., life stage, size, and genotype) and simulate interactions among them and with their surroundings (Grimm and Railsback 2005). Herein, we employed microsatellite markers and an individual-based model (IBM) to estimate the fine-scale SGS of a $T$. recurvata population 
scattered on neighboring trees and to understand the emergence of the observed empirical patterns of genetic variation over colonization time and across landscapes with distinct tree densities.

\section{MATERIAL AND METHODS}

\section{Model species}

Tillandsia recurvata is an epiphytic bromeliad distributed in the American continent. This species is known by several popular names (e.g., ball-moss, Jamaican ball moss, musgo de bola, heno de bola, galinita, and cravo-do-mato; Birge 1911), which refer to the 'dry aspect of leaves and the intense clonal growth from leaf axils that forms a ball-like shape. Particularly found in open biomes from Argentina and Brazil to the southern United States (Smith and Downs 1977; GBIF 2017), the high abundance and dominance of $T$. recurvata in epiphytic communities constitutes a characteristic feature of landscapes and has long attracted the interest of naturalists and researchers (e.g. Birge 1911; McWilliams 1992; Flores-Palacios et al. 2014; Orozco-Ibarrola et al. 2015). Studies have described T. recurvata as the most xerophytic species of tropical and subtropical epiphytes (e.g., Benzing 2000; 2012), with "probably the greatest adaptability of any plant in the Western Hemisphere" (Foster 1945:14). Several ecological and reproductive features, such as small size, absorbent leaf scales, CAM photosynthesis, wind-dispersed seeds, the spontaneous self-pollination underpinning its cleistogamous flowers, and intense clonal growth have allowed $T$. recurvata to generate large populations even on isolated trees within recently disturbed landscapes (Soltis et al. 1987; Smith et al. 1989; Orozco-Ibarrola et al. 2015; ChilpaGalván et al. 2018). Each host tree can thus act as an isolated patch of habitat scattered in a harsh matrix (Southwood and Kennedy 1983; Burns 2007), determining that the majority of dispersed seeds of T. recurvata fall close to the mother and establish on the same host tree (e.g., Trapnell et al. 2004; Victoriano-Romero et al. 2017; Torres et al. 2018).

The high adaptability of $T$. recurvata has fostered the species distribution in humandisturbed regions, forming large populations in urban landscapes, actively growing on fences and electric light wires (e.g., Martins 2009; Chaves et al. 2016). Such great abundance has led some authors to consider T. recurvata as an "epiphytic weed," and some of them even sought to describe herbicides and other techniques to control its spreading (e.g., Claver et al. 1983; Bartoli et al. 1993). Although T. recurvata cannot be classified as a parasite, studies have listed deleterious effects that massive populations may have on co-occurring epiphytes and host trees, as it competes for light with new shoots, modifies barks, and affects seedling growth (e.g., Birge 1911; Flores-Palacios et al. 2014; Aguilar-Rodriguez et al. 2016). Therefore, the reproductive 
biology and opportunistic behavior of $T$. recurvata make this species a good model species for studying the temporal and spatial spreading dynamics of weeds.

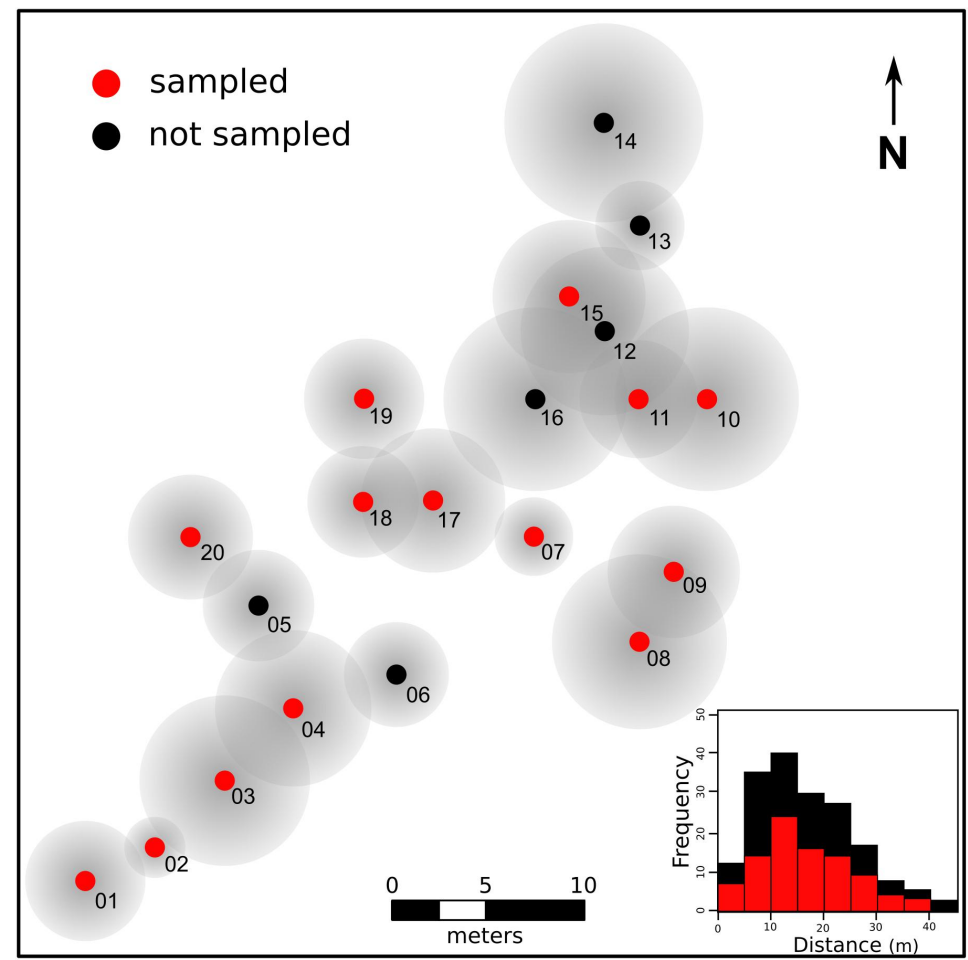

Figure 1. Spatial distribution and histogram of the frequency of distance classes of pairwise trees within the studied landscape. Numbers refer to IDs of trees hosting the Tillandsia recurvata populations analyzed. Gray circles around each dot are representations of the crown area of each tree. Red dots and bars represent, respectively, the location and frequency of distances among pairs.

\section{Empirical genetic data}

The empirical study took place in an anthropically transformed landscape of ca. 0.2 ha in southwest Brazil $\left(-21.244289^{\circ} \mathrm{S},-48.300486^{\circ} \mathrm{W}\right.$; Fig. 1) composed of a grove of 20 cultivated Handroanthus spp. (Bignoniaceae) of similar ages (ca. 20 years) and growing from 2.5 to $47.5 \mathrm{~m}$ from each other, surrounded by a grassland matrix (ca. 100 tree/ha; Fig. 1). We sampled a total of 224 individuals of $T$. recurvata growing on 14 neighboring trees (16 individuals per tree; hereafter referred to as "subpopulations") and extracted total genomic DNA from leaf samples according to Tel-Zur et al. (1999). We characterized the multi-locus genotype (MLG) of each individual using seven SSR loci designed for other species and cross-amplified them as described by Chaves et al. (2018). We avoided sampling clones by collecting individuals at distinct branches of each host tree. Indeed, clonal individuals of $T$. recurvata (i.e., ramets) can be easily distinguished because they are formed on leaf axils and remain attached, conferring the typical "ball" shape of the species (Birge 1911). 
To describe the genetic diversity within each $T$. recurvata subpopulation, we calculated the number of alleles $(A)$, allelic richness $\left(A_{R}\right)$, the private number of alleles $\left(A_{P}\right)$, expected $\left(H_{E}\right)$ and observed heterozygosity $\left(\mathrm{H}_{\mathrm{O}}\right)$, and inbreeding coefficient $\left(F_{\mathrm{IS}}\right)$ and tested for departures from Hardy-Weinberg expectations using the $\mathrm{R}$ statistical package diveRsity (Keenan et al. 2013). Furthermore, we tested if subpopulations were isolated-by-distance using a Mantel test with Slatkin's linearized $F_{\mathrm{ST}}\left(F_{\mathrm{ST}} /\left(1-F_{\mathrm{ST}}\right)\right)(1995)$, Nei's (1972), Edward's (1971), and Reynold's (1983) pairwise genetic distances and the logarithm of geographical distance, with 1,000 replications, using the R statistical packages poppr (Kamvar et al. 2014) and pegas (Paradis 2010). We also measured pairwise subpopulation differentiation $\left(F_{\mathrm{ST}}\right)$ and tested the hierarchical partition of genetic variance among and within sampled subpopulations by performing an analysis of molecular variance (AMOVA; Excoffier et al. 1992), using the R statistical package poppr (Kamvar et al. 2014).

To investigate the spatial genetic structure (SGS) within the $T$. recurvata population sampled, we adopted two distinct approaches, one explicitly considers the spatial distance among individuals, and another takes into account the discrete distribution of this epiphyte among distinct tree crowns. In the first approach, we tested whether the distance among T. recurvata individuals, disregarding tree crowns, affect their relatedness. For this, we estimated the kinship coefficient ( $\mathrm{F}_{\mathrm{ij}}$; Loiselle et al. 1995) between all pairs of individuals sampled within seven distance classes, each comprising the same number of pairs, using the $\mathrm{R}$ package RClone (Bailleul et al. 2016). To quantify the SGS under this approach, we calculated the $\mathrm{S}_{\mathrm{p}}$ statistics (i.e. the ratio between the kinship decay by increasing geographic distances and the mean kinship within the first interval distance; Vekemans and Hardy 2004) and tested the statistical significance of mean kinship coefficient values in each distance class (confidence interval: $95 \%$ ) by randomly shuffle $(1000 \times)$ individual locations (Vekemans and Hardy 2004). In the second SGS approach, we rather tested whether individuals within subpopulations are more related than across the whole population. For this, we first calculated the $F_{i j}$ for all sampled pairs of individuals within each subpopulation $\left(\mathrm{F}_{\mathrm{ij}}^{\mathrm{ij}}{ }^{\text {sub }}\right)$ and also for all sampled pairs in the whole population $\left(\mathrm{F}_{\mathrm{ij}}{ }^{\text {pop }}\right)$, using the $\mathrm{R}$ package RClone (Bailleul et al. 2016). We then calculated the ratio of $F_{i j}$ sub divided by $F_{i j}$ pop $\left(\mathrm{F}_{\mathrm{ij}}^{\mathrm{sub}} / \mathrm{F}_{\mathrm{ij}}{ }^{\text {pop }}\right)$ for each subpopulation. Lastly, we quantified the partitioning of genetic composition of the whole population by calculating the turnover of alleles and multi-locus genotypes among subpopulations (MLG; see Harrison et al. 1992; Jost 2007), using the R statistical package vegetarian (Charney and Record 2012). 


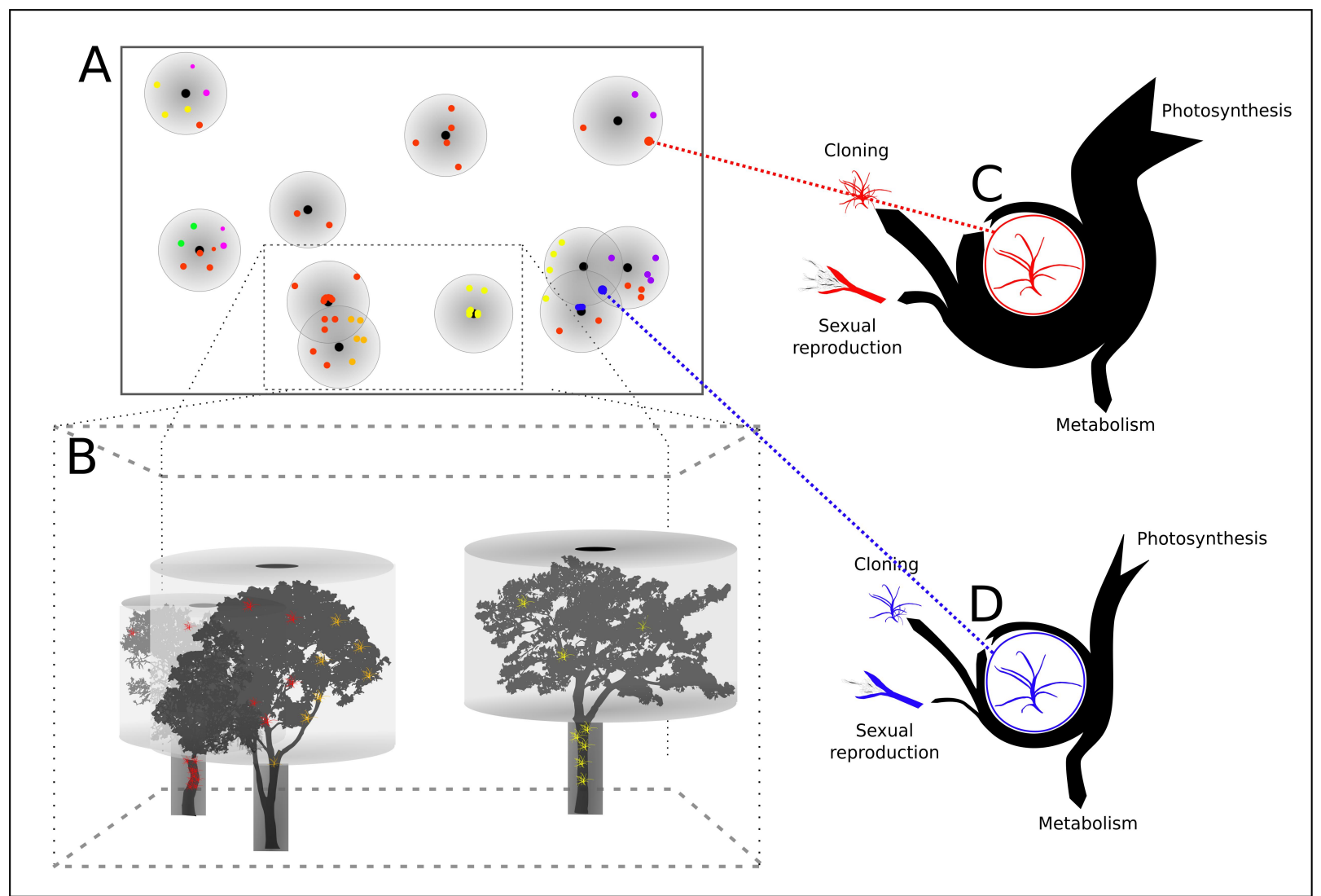

Figure 2. Schematic representations of the individual-based model (IBM) simulating a landscape of 0.40 hectares. Figure in A is a representation similar to what we see in the IBM in NetLogo software. Points with distinct colors represent Tillandsia recurvata individuals of distinct genetic lineages (MLLs). Larger circles with a gradient gray color and concentric smaller black circles represent the crowns of distinct trees. Figure in B shows a 3D representation of the cut area of the landscape in A. Figures in C and D show the energy budget expected along a year of development of $T$. recurvata individuals attached to branches with, respectively, low and high shading levels. The arrow nocks and arrowheads represent energy inputs and outputs, respectively. The width of the arrows indicates the amount of energy being earned, lost, or accumulated.

\section{Individual-based modeling}

We implemented an IBM in NetLogo 6.0.1 (Wilensky 1999) and outlined it following the ODD (Overview, Design concepts, Details) protocol formulated by Grimm et al. (2006, 2010; see Appendix S1 in Supporting Information). The model simulates a static landscape composed of multiple $0.01 \mathrm{~m} 2$ patches of soil with scattered trees that are colonized by multiple seeds of $T$. recurvata with distinct MLGs (based on empirical alleles). Such seeds annually reach the landscape from outside (hereafter referred to as 'regional seeds') by wind dispersal, reproduce by self-fertilization and grow by producing new ramets (clonal growth) on trees within the landscape (Fig. 2). The wind speed was set as a modelling unit that quantifies the total distance (in units of 'landscape patches') seeds are carried by wind at each time step of the model. The colonization 
dynamics of the model is primarily based on the 'energy budget' of $T$. recurvata, which quantifies, in a simplified approach, the amount of energy each individual takes up by photosynthesis and expends during its life cycle through metabolism, growth, and reproduction, depending on the shading rate of its attachment site (Fig. 2). The energy budget approach is based on the Dynamic Energy Budget theory of Kooijman (2010) and has been adopted in IBMs to generally describe how individuals acquire and expend energy with simple and sufficient realism (e.g. Sibly et al. 2013; Johnston et al. 2014; van deer Vaart et al. 2016). In our study, the capacity of each $T$. recurvata individual to reproduce and generate seeds depends on the amount of energy stocked up until the reproductive season (Fig. 2). In this IBM, we assume that each seed that successfully develops and thrives in the landscape forms a multi-locus lineage (MLL) of multiple descendants, which can be traced back to the ancestor. Each new seed produced within the landscape can also be randomly wind-dispersed by chance to other trees, but new ramets are always attached to the same host tree. Each MLL often groups multiple MLGs due to heterozygous loci and mutation events. A source of genetic variation within MLLs is simulated by a varying mutation-rate (from $10^{-2}$ to $10^{-6}$ ) that simulates DNA replication slippages of SSR loci.

The IBM is based on five parameters with a priori estimates based on general assumptions or previous knowledge on the species (see Table 1). We performed a Global Sensitivity Analysis to test whether summary statistics - i.e., the mean number of alleles $(\mathrm{K})$, mean range of allele size $(\mathrm{R})$, mean expected heterozygosity $(\mathrm{H})$, mean inbreeding coefficient $\left(F_{\text {IS }}\right)$, global subpopulation differentiation $\left(F_{\mathrm{ST}}\right)$, and mean modified Garza-Williamson statistic $(\mathrm{NGW}$; Garza and Williamson 2001; Excoffier et al. 2005) - as well as T. recurvata abundance and the total number of MLL, are differently affected by the variation of each parameter. To improve the IBM model accuracy, we estimated model parameters using an ABC framework ('Approximate Bayesian Computation'; Csilléry et al. 2010). From a representation of the empirical landscape studied, we simulated one million SSR data sets varying five parameters, calculated six summary statistics, and obtained posterior estimates of each parameter based on 319,539 retained simulation data most resembling the empirical SSR data (see Appendix S2 for further information). 
Table 1. Individual-based model parameters of Tillandsia recurvata populations. Prior ranges are based on literature or previous simulations tests. Posterior ranges are based on the results of $\mathrm{ABC}$, while estimated values are based on the accuracy of each parameter value obtained by the $\mathrm{ABC}$ cross-validation tests.

\begin{tabular}{|c|c|c|c|c|c|}
\hline Parameter & Definition & $\begin{array}{c}\text { Prior range } \\
\text { (min-max) }\end{array}$ & $\begin{array}{c}\text { Prior } \\
\text { distribution }\end{array}$ & $\begin{array}{c}\text { Posterior } \\
\text { range }(\mathrm{CI} \\
95 \%)\end{array}$ & Reference \\
\hline $\begin{array}{c}\text { Regional seed } \\
\text { rain }\end{array}$ & $\begin{array}{c}\text { Number of seeds that arrive } \\
\text { on the landscape at each } \\
\text { reproductive season }\end{array}$ & $\begin{array}{c}100-500 \\
\text { seeds/year }\end{array}$ & uniform & $179-197$ & Previous simulations tests \\
\hline $\begin{array}{c}\text { Wind speed } \\
\text { The magnitude of seed } \\
\text { dispersal } \\
\text { (non-dimensional values) }\end{array}$ & $1-20$ units* & uniform & $15.06-15.71$ & Previous simulations tests \\
\hline $\begin{array}{c}\text { Mutation rate } \\
\text { Average SSR mutation-rate }\end{array}$ & $\begin{array}{c}10^{-6}-10^{-2} \\
\left(\mathrm{mean}=10^{-4} ;\right. \\
\left.\mathrm{sd}=10^{-3.5}\right)\end{array}$ & normal & $10^{-3.10-10^{-2.85}}$ & $\begin{array}{c}\text { Anmarkrud et al. 2008; } \\
\text { Udupa and Baum 2001; } \\
\text { Marriage et al. 2009 }\end{array}$ \\
\hline $\begin{array}{c}\text { Germination } \\
\text { rate }\end{array}$ & Seed germination rate & $0.0083-0.30$ & uniform & $0.233-0.243$ & $\begin{array}{c}\text { Bernal et al. (2005); } \\
\text { Chilpa-Galván et al. } \\
\text { (2018) }\end{array}$ \\
\hline $\begin{array}{c}\text { Capture } \\
\text { probability }\end{array}$ & $\begin{array}{c}\text { Probability of a seed be } \\
\text { captured in the canopy }\end{array}$ & $0.01-0.30$ & uniform & $0.191-0.204$ & Chaves \& Rossatto 2020 \\
\hline
\end{tabular}

* Each wind speed unit is multiplied by five to refer to the amount of 'landscape patches' in the model the

\section{Colonizing over time and across landscapes}

We used the posterior range of the estimated parameters of the IBM (see Table 1) to simulate the temporal dynamic of genetic structuring during the spreading of a $T$. recurvata population (hereafter referred as 'time simulation') and the spatial dynamics of genetic structuring of populations scattered in landscapes with distinct tree densities (hereafter referred to as 'density simulation'). We performed 10,000 times simulations for 50 years of spreading of $T$. recurvata populations on an empirical landscape representation (see Fig. 1), and 100,000 density simulations of $T$. recurvata populations after ten years of spreading in ca. 0.40 hectares landscapes with five to 150 trees (maximum amount of trees that occupy the landscape) with random heights and same crown sizes. After each year in time simulations, we recorded the individual and MLL abundances, as well as the MLG, MLL, and origins (from clonal growth or sexual reproduction; hereafter referred to as 'clones' and 'seeds' individuals) of up to $15 T$. recurvata individuals established on each host tree representation from the empirical study. The same data were recorded after the $10^{\text {th }}$ year for up to 15 random trees for density simulations. 
inbreeding coefficient $\left(F_{\mathrm{IS}}\right)$, and the global subpopulation differentiation $\left(F_{\mathrm{ST}}\right)$ using the ARLSUMSTAT console version of Arlequin 3.1; the MLG and MLL turnovers among subpopulations (T/O $\mathrm{O}_{\mathrm{MLG}}$ and $\mathrm{T} / \mathrm{O}_{\mathrm{MLL}}$ ), using the $\mathrm{R}$ package vegetarian (Harrison et al. 1992; Jost 2007); the kinship coefficient $\left(\mathrm{F}_{\mathrm{ij}}\right.$; Loiselle et al. 1995) of each subpopulation $\left(\mathrm{F}_{\mathrm{ij}}{ }^{\text {sub }}\right)$ divided by the kinship of the whole population $\left(\mathrm{F}_{\mathrm{ij}}{ }^{\text {pop }}\right)$ in each simulation (i.e., $\mathrm{F}_{\mathrm{ij}}$ sub/pop); and the $\mathrm{S}_{\mathrm{p}}$ statistics considering seven distance classes as in the empirical study (Vekemans and Hardy 2004) using the R package RClone (Bailleul et al. 2016).

\section{RESULTS}

\section{Empirical population genetics}

We observed moderate levels of genetic diversity within each subpopulation, despite high endogamy, and high genetic structure among the studied subpopulations. The number of alleles (A) ranged from 19 to 30, while allelic richness $\left(A_{R}\right)$ ranged from 2.20 to 3.54, and the private number of alleles $\left(\mathrm{A}_{\mathrm{P}}\right)$ was up to 2 per subpopulation (see Table S3 in Appendix S2). Expected $\left(\mathrm{H}_{\mathrm{E}}\right)$ and observed $\left(\mathrm{H}_{\mathrm{O}}\right)$ heterozygosities ranged from 0.27 to 0.51 , and from 0 to 0.20 , respectively (Table S1). The inbreeding coefficients $\left(F_{\text {IS }}\right)$ were significant and very high, ranging from 0.52 to 1.0 per subpopulation, due to significant heterozygosity deficit under HardyWeinberg equilibrium (Table S1). Pairwise subpopulation differentiation $\left(F_{\mathrm{ST}}\right)$ ranged from 0.01 to 0.31 (Fig. S1). The Mantel test indicated a significant although weak isolation-by-distance (IBD) pattern among subpopulations only when using Edward's genetic distances $(r=0.243 ; \mathrm{p}=$ 0.032). AMOVA analysis, in turn, showed lower genetic variance among subpopulations (17.26\%) than within subpopulations $(82.74 \%)$ but was significantly greater than zero $(\mathrm{p}<0.001)$.

The highest kinship ( $\mathrm{F}_{\mathrm{ij}}$ ) was observed at the smallest distance interval (up to $2.5 \mathrm{~m}$ ), which is significantly higher than expected by chance ( $p<0.05$; Fig. $3 \mathrm{~A})$. Kinship coefficients peaked outside the $95 \%$ confidence interval at almost all distance classes, showing a remarkable decay at three out of four distance classes higher than ca. 13 meters (Fig. 3A), and a significant spatial genetic structure $\left(S_{p}=0.024 ; p<0.001\right)$. The $F_{i j}$ within subpopulations (i.e., $F_{i j}{ }^{\text {sub }}$ ) was, in average, almost 15 times higher than the kinship of the population $\left(\mathrm{F}_{\mathrm{ij}}{ }^{\mathrm{pop}}=0.002\right)$. We detected allelic and MLG turnovers of 0.031 and 0.537 , respectively. MLGs were evenly spaced among subpopulations, generally with one distinct dominant MLG in most subpopulations (Fig. 3B). 


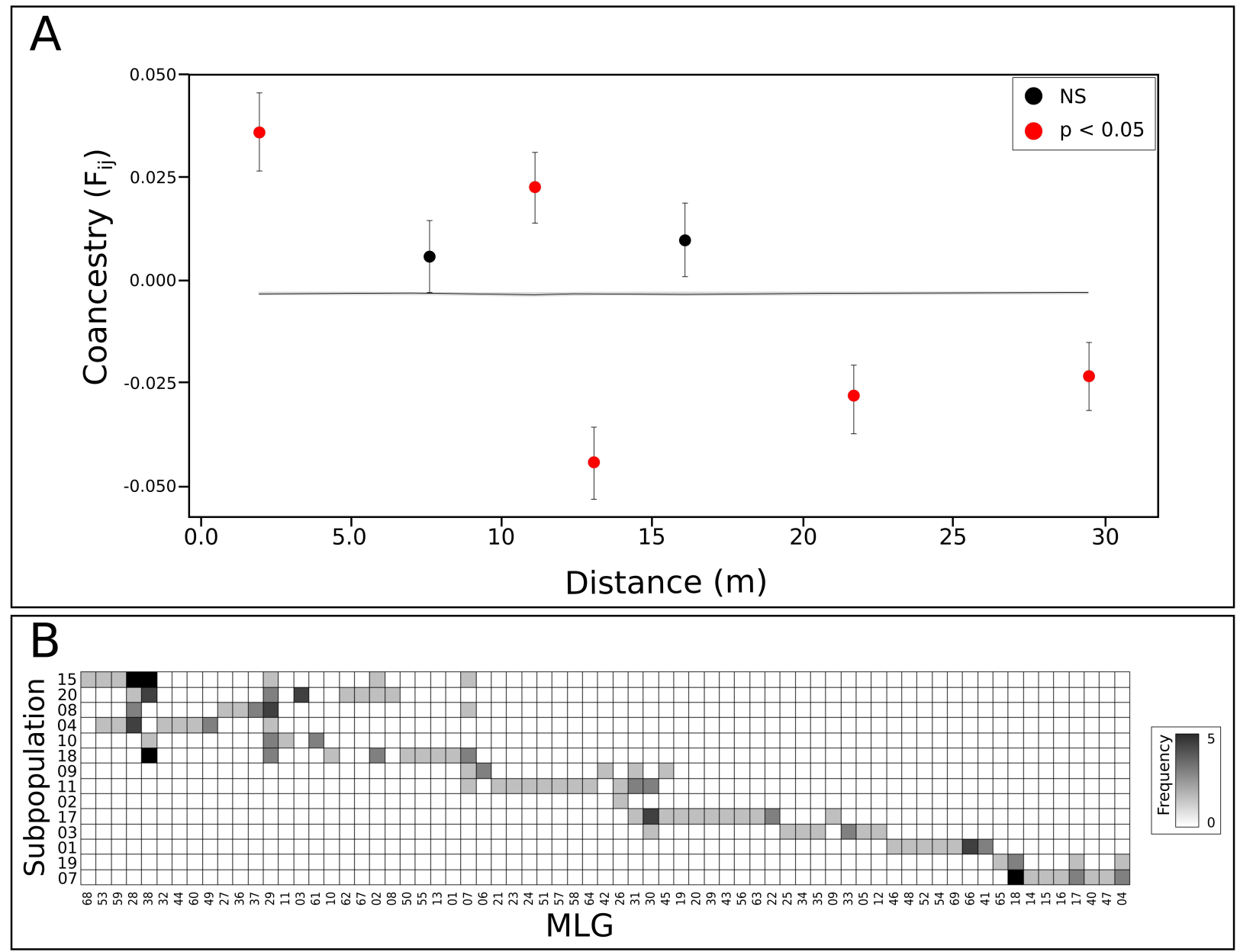

Figure 3. Spatial genetic structure of the empirical Tillandsia recurvata population. A: correlogram from spatial autocorrelation analysis using the correlation coefficient Fij (Loiselle et al. 1995) and seven distance classes. The grey area represents the null hypothesis, and its $95 \%$ confidence intervals, with no spatial genetic structuring, and black lines around each average Fij values represent their standard errors. B: Adjacency matrix showing the occurrence of each genotype (MLG) of Tillandsia recurvata (columns) on subpopulations corresponding to each sampled tree (rows). Grey gradient colors represent the frequency of each genotype per subpopulation.

\section{Individual-based model}

The sensitivity test performed for the IBM model showed that high mutation rates of SSR markers can significantly decrease the inbreeding coefficient $\left(F_{\text {IS }}\right)$ and subpopulation differentiation $\left(F_{\mathrm{ST}}\right)$ (Figure S2). This test also suggests that strong winds, massive regional seed rains, and high rates of germination and seed capturing likely reduce the SGS within $T$. recurvata populations (Figure S2). Based on the ABC framework, we estimated a range of parameters' values to be randomly used in time and density simulations (Table 1). Almost all summary statistics demonstrate a deep sensitivity to parameters variation (Fig. S2). However, parameters estimation through the cross-validation showed a significant correlation between real and estimated values $(\mathrm{p}<0.001)$, wind speed and capture probability were, respectively, the 
parameters most and least accurately predicted by the model (Fig. S3). From 319,539 simulations used for the cross-validation, this analysis accepted the parameter combination of 1,598 simulations. We found five significant correlations among parameters in accepted simulations (Table S2). Capture probability and regional seed rain $(\mathrm{r}=-0.430)$ are the most correlated parameters.
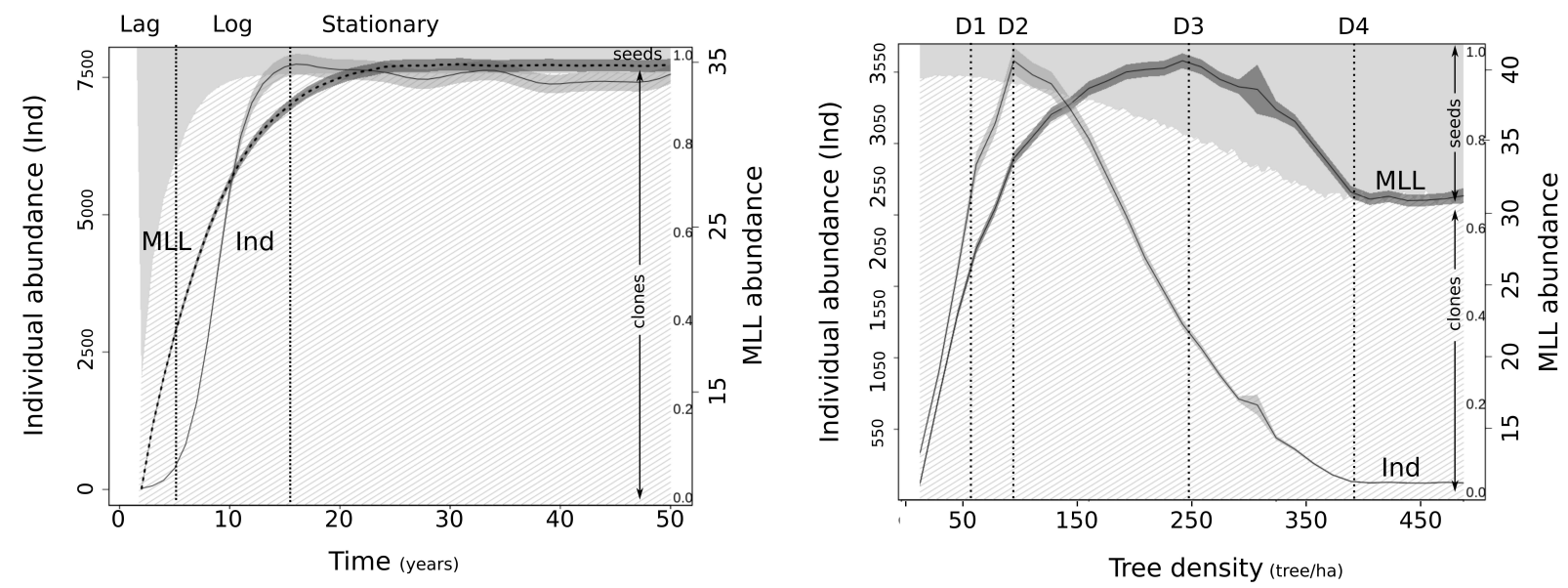

Figure 4. Variation of individual and multi-locus lineages (MLL) abundances of Tillandsia recurvata, as well as its clones/seeds proportion, according to time of colonization and tree density. Stages of individual abundance development by time are highlighted as "Lag", "Log", and "Stationary". Critical tree densities for parameters variation are highlighted as "D1", "D2", "D3", and "D4".

Individual abundance varies through time, exhibiting three distinct phases, here named Lag (ca. 0 to 5 years), Log (ca. 5 to 15 years), and Stationary (higher than 15 years) phases (Fig. 4). During the Lag phase, the individual abundance is maintained at very low values, while the MLL abundance and clonal proportion increase along with the gradual rise in $F_{\text {IS }}$ and $\mathrm{A}$ and the decay in T/O $\mathrm{O}_{\mathrm{MLG}}$ (Fig. 4 and 5). Values of $F_{\mathrm{ST}}$ reach a maximum of ca. 0.40 in the middle of the lag phase, followed by a peak in $\mathrm{F}_{\mathrm{ij}}$ sub/pop and $\mathrm{S}_{\mathrm{p}}$ (ca. 20 and 0.09 , respectively) and a rapid drop in $\mathrm{F}_{\mathrm{ij}} \mathrm{pop}^{\mathrm{at}}$ at the end of this phase (from ca. 0.013 to 0.002; Fig. 5). Our simulations show that individual abundance multiplies, reaching a peak at the end of the Log phase (from some dozens to ca. 7,500 individuals), while $S_{p}$ suffers large drops until the end of the stage (from ca. 0.090 to 0.045; Fig. 5). In the middle of the Log phase, the proportion of clones and $F_{\text {IS }}$ reach their maximum (ca. 0.98 and 0.80 ) while $F_{\mathrm{ST}}$ and T/O $\mathrm{O}_{\mathrm{MLG}}$ reach their minimum (ca. 0.20 and 0.50; Fig. 5). For up to 20 years of colonization (Stationary phase), simulations show that individual abundance, and many other measured variables, suffer only small variations (Fig. 4 and 5). MLL abundance and A reach to their maximum of ca. 35 MLLs and 20.5 alleles, respectively, a few years after the beginning of the Stationary phase (Fig. 5 and 6). From the Log to Stationary phases, values of $F_{\mathrm{ij}}{ }^{\text {pop }}$ vary between 0.0004 and 0.0013 in cycles of ca. of 4 years. 

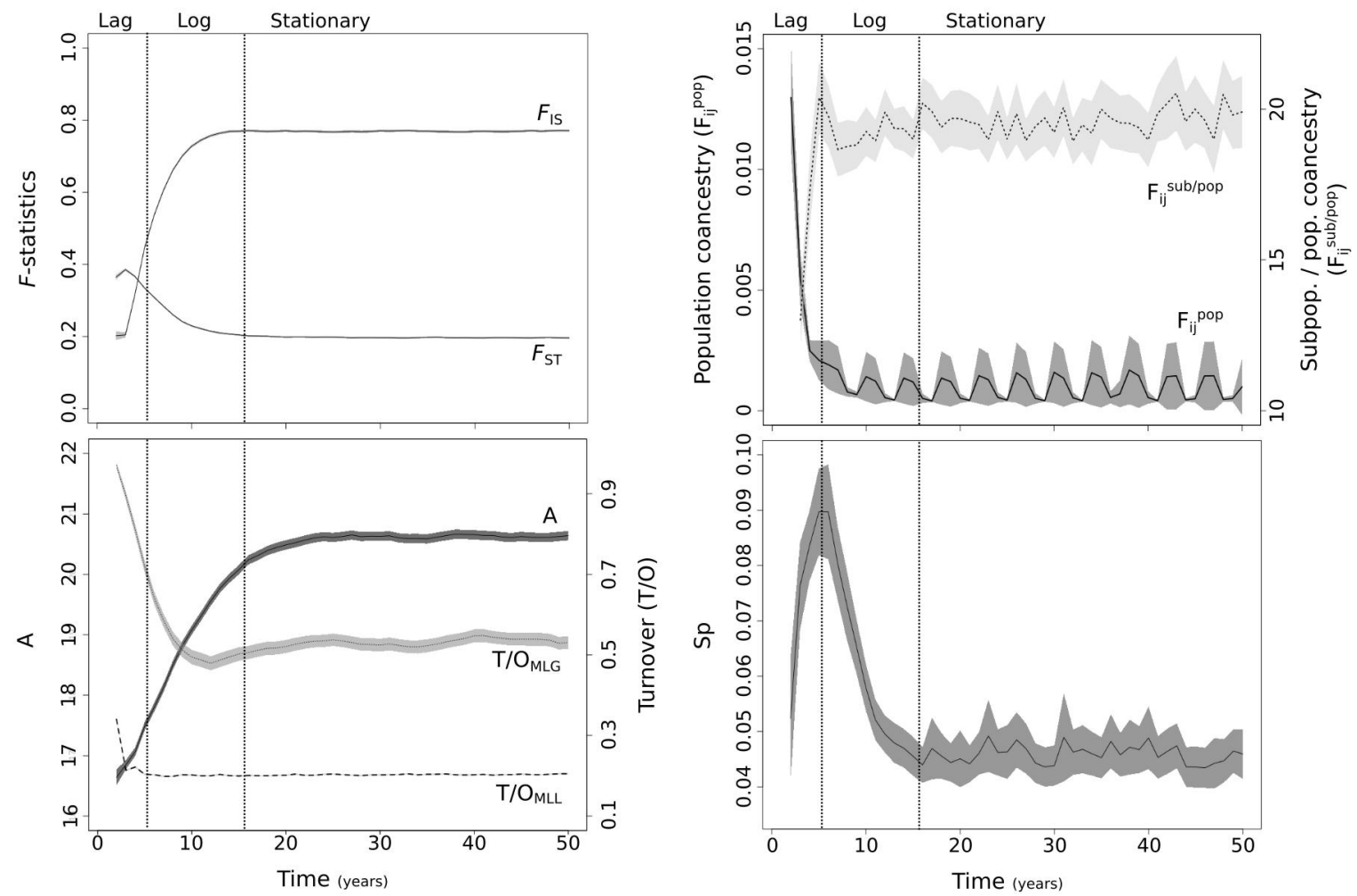

Figure 5. Temporal dynamic of genetic indices of Tillandsia recurvata population. Lines and grey areas around them represent the average and $95 \%$ confidence intervals of 10,000 simulations. Stages of individual abundance development by time are highlighted as "Lag", "Log", and "Stationary".

Density simulations show greater variance and less stability than time simulations. We found that increasing tree densities of up to ca. 50 trees/ha (D1 in Figs. 4 and 6) lead to the greatest proportion of clonal individuals (ca. 0.90, see Fig. 4) and a peak of $F_{\text {IS }}$ (ca. 0.85) and the number of alleles (ca. 14). At the same time, $F_{\mathrm{ST}}, \mathrm{T} / \mathrm{O}_{\mathrm{MLG}}, \mathrm{T} / \mathrm{O}_{\mathrm{MLL}}, \mathrm{F}_{\mathrm{ij}}$ pop, as well as the $\mathrm{S}_{\mathrm{p}}$ statistics reached their lowest values (ca. 0.45, 0.35, 0.28, 0.0005, and 0.075 respectively, see Fig. 6). Our simulations also showed that the peak of individual abundance (ca. 3600 individuals) occurs at ca. 95 trees/ha (D2 in Fig. 4) and that increasing tree density up to 400 trees/ha (D4 in Fig. 4) leads to a reduction of up to $95 \%$ of individuals. Intermediate tree densities of ca. 250 trees/ha (D3 in Fig. 4) foster the greatest MLL abundances (ca. 40 MLLs), and the highest values of $F_{\mathrm{ST}}$ (ca. 0.65), $\mathrm{F}_{\mathrm{ij}}$ sub/pop (ca. 30), and $\mathrm{S}_{\mathrm{p}}$ statistics (ca. 0.11). A steep decay in the proportion of clones (from ca. 0.95 to 0.65 ), between 50 and 400 trees/ha (D1 and D4 in Fig. 4), is followed by the decay of $F_{\text {IS }}$ (ca. 0.85 to 0.70 ) and number of alleles (ca. 14 to 10 ), and the increase of $F_{\mathrm{ST}}$ (ca. 0.45 to 0.65 ), $\mathrm{T} / \mathrm{O}_{\mathrm{MLG}}$ (ca. 0.35 to 0.90 ), $\mathrm{T} / \mathrm{O}_{\mathrm{MLL}}$ (ca. 0.25 to 0.90 ), and $\mathrm{F}_{\mathrm{ij}} \mathrm{pop}$ (ca. 0.0005 to $0.0040)$. 

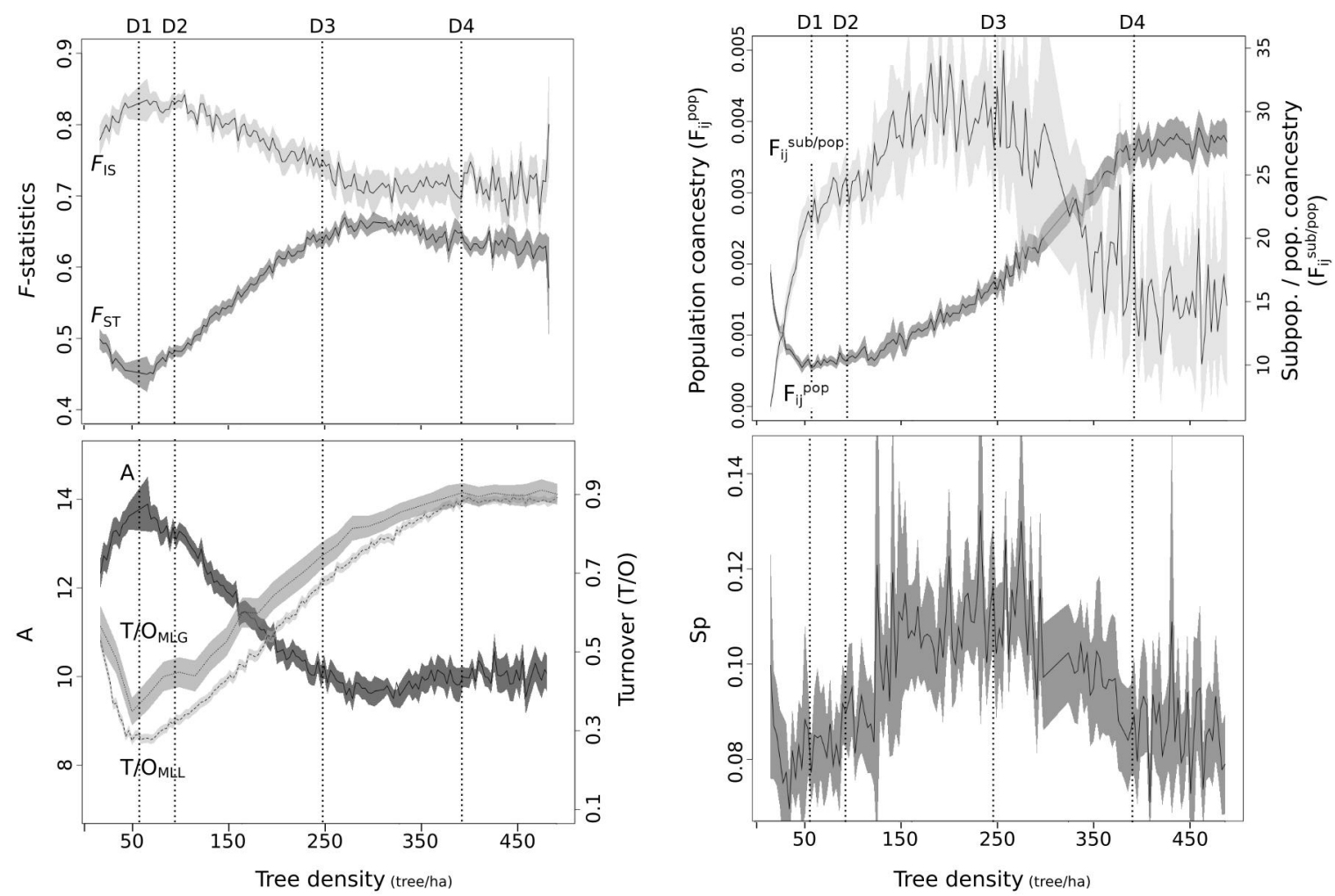

Figure 6. The spatial dynamic of genetic indices of Tillandsia recurvata population over landscapes with distinct tree densities. Lines and grey areas around them represent the average and $95 \%$ confidence intervals of 100,000 simulations. Vertical dotted lines highlight key values (D1-D4) of tree densities according to the studied indices.

\section{DISCUSSION}

In this study, we integrated empirical and simulated genetic data to provide insights into the dynamics of genetic structuring of populations of an epiphytic weed (i.e., Tillandsia recurvata) distributed into human-transformed landscapes. Our empirical results show a relatively high spatial genetic structure (SGS) for T. recurvata within a small anthropic landscape (c.d. 0.2 ha) with low tree density, suggesting that trees may be considered as habitat units of epiphytic systems (Flores-Palacios \& García-Franco 2006). The simulated data provided by our individualbased model (IBM) explicitly describes the temporal dynamics of the empirical T. recurvata population, revealing the highest levels of SGS at the very beginning of the colonization process. The IBM also points out that the landscapes with the highest tree densities tend to harbor populations of T. recurvata with the strongest SGS patterns. Below, we discuss our findings based on the ecological features of this species, highlighting the importance of understanding the spatiotemporal dynamics of genetic structuring and the eco-evolutive consequences of human transformations on landscapes. 


\section{Fine-scale genetic structure}

Our empirical study in an anthropic landscape shows a relatively pronounced SGS for $T$. recurvata at a fine-scale (ca. $2,000 \mathrm{~m}^{2}$ ), as indicated by the significant $\mathrm{S}_{\mathrm{p}}$ statistics, high subpopulation differentiation, and the almost $15 \times$ greater kinship among individuals within subpopulations compared to the kinship in the whole population. Such SGS likely arises as an outcome of the breeding system and life form of T. recurvata, which present limited local gene flow, resulting in a significant isolation-by-distance, persistence of private alleles in six out of 14 studied subpopulations, as well as high turnover of multi-locus genotypes (MLGs). Indeed, SGS at fine scales often results from limited gene flow (Vekemans and Hardy 2004; Ward 2006), and other studies have reported similar genetic patterns for selfing (e.g., Pettengill et al. 2016; Atwater et al. 2018), cloning (e.g., Li and Dong 2009; Atwater et al. 2018), epiphytic (e.g., Trapnell et al. 2004; Ren et al. 2017; Torres et al. 2018), and fast-growing plants (e.g., Barluenga et al. 2011; Charbonneau et al. 2018). Our results indicate that specific habits and breeding systems can foster the structuring of populations, even for opportunistic and widespread plants.

Our results also indicate that the $T$. recurvata spreading is contemporary and gradually conducted by several sources following a phalanx pattern, rather than by a single leading subpopulation (see Hewitt 1996), considering that many MLGs have the same alleles. Still, few subpopulations share the same MLGs (i.e., low allelic turnover but high MLG turnover). These results may suggest that distinct native populations of $T$. recurvata of the surroundings may be responsible for colonizing our focal landscape massively. Under such conditions, selfing reproduction and clonal growth may lead to a partial, and perhaps transitory, isolation among subpopulations of T. recuvata (see Ward 2006). Beyond the effect of breeding system and life form, the relatively high fine-scale SGS of $T$. recurvata may also result from following founder events on each host tree (see Hewitt 1996; Ward 2006). Nevertheless, the genetic drift resulting from consecutive founder events, as well as the increasing amount of seeds released from large subpopulations, may intensify the metapopulation dynamics of repeated local extinction and recolonization events, which may reduce the population structuring over time (Baker 1955, Pannell and Barrett 1998; Razanajatovo et al. 2016).

\section{SGS over time}

The genetic structure dynamics of $T$. recurvata throughout the time simulations of our IBM, as represented by the Lag, Log, and Stationary phases for distinct genetic parameters, resembles diffusion models of invasion for weedy species in new disturbing landscapes (e.g., Counsens and Mortimer 1995). In the first few years (i.e., Lag or stationary phase; here, up to the 
$5^{\text {th }}$ year), only a few individuals successfully establish in the landscape, despite the constant input of new genetic lineages (MLLs) per reproductive season. The mismatch between the small number of $T$. recurvata individuals and the increasing number of MLLs reduces the average kinship in the population and leads to a peak of genetic structuring and differentiation among subpopulations. The continuous establishment of new MLLs within the landscape underlies an increasing production of new ramets by clonal growth, that may help to overcome demographic stochasticity and the Allee effect (Loreau at al. 2013; Santos et al. 2014; van Kleunen 2018), raising the individual abundance and inbreeding coefficient $\left(F_{\mathrm{IS}}\right)$ to their highest values in the $\log$ phase (between the $5^{\text {th }}$ and $15^{\text {th }}$ year).

The rapid increase in individual abundance during the log phase drives the interchange of seeds and MLGs among subpopulations, leading to a reduction in subpopulation differentiation and structuring. However, the stabilization in the proportion of clones in this phase limits the establishment of a higher number of individuals and MLLs, leading to a steady level in all calculated variables by the $15^{\text {th }}$ to $20^{\text {th }}$ year (Stationary phase). According to our results, the reduction in subpopulation differentiation and structuring during the Log phase, followed by stabilization at lower values, may indicate that $T$. recurvata meta-populations behave as a source population after the $15^{\text {th }}$ year of colonization, supporting their rapid spreading into potential new areas. Notwithstanding the specific characteristics of each species, this temporal pattern is typical for other opportunistic organisms under optimal conditions. As observed for T. recurvata, a fast increase and stabilization in the individual abundance of populations and communities in static systems are expected (see Spruch et al. 2019). On the other hand, a landscape with growing trees may lead to a gradual increase in epiphyte abundance with no signs of saturation (Einzmann and Zotz 2017; Spruch et al. 2019). But, given the preference of T. recurvata for dry and open environments, canopies with increased shading, as provided by dense forests or a reforestation system, could have an opposite effect, as we show the following.

\section{SGS across landscapes with distinct tree densities}

Results from simulations under distinct tree densities show that the highest abundance of $T$. recurvata individuals occur at tree densities close to those observed from the empirical data (ca. 100 trees/ha). Lower tree densities (<100 trees/ha) led to a decrease in SGS may due to a reduction in habitat amount, since each host tree counts as a habitat patch for the species (e.g., Snäll et al. 2005; Belinchón et al. 2017). On the other hand, under higher tree densities (>50 trees/ha), the increasing number of trees may maximize the SGS in $T$. recurvata due to a strengthening of the resistance for seed dispersal among subpopulations. Under these conditions, 
winds are typically stronger and support higher wind-dispersal distances in open areas (see Nathan et al. 2002; Cousens et al. 2008). Indeed, studies implementing IBM approaches for distinct biological systems have shown that habitat amount and resistance to gene flow across landscapes strongly influence SGS among subpopulations (e.g., Cushman et al. 2012; Jackson and Fahrig 2016). However, even under higher tree densities ( $>250$ trees/ha), T. recurvata may have reduced levels of genetic structuring $\left(\mathrm{S}_{\mathrm{P}}\right)$ and kinship differentiation among subpopulations $\left(\mathrm{F}_{\mathrm{ij}}^{\mathrm{sub} / \mathrm{pop}}\right)$ likely due to a drop in the overall individual abundance and an underlying increase in the average kinship in population. Moreover, our simulations show that very few genetic lineages of $T$. recurvata successfully establish only at the edges of the landscapes with the highest tree densities ( $\sim 50$ trees/ha). Consequently, the established subpopulations often have individuals of the same lineage and, therefore, low genetic differentiation among each other.

The stronger spatial genetic structure of T. recurvata populations in landscapes with high tree densities is likely a consequence of the species preference for dry and open ecosystems (e.g., Smith et al. 1989; Orozco-Ibarrola et al. 2017; Chilpa-Galván et al. 2018). Indeed, T. recurvata populations are often reduced to a few individuals constrained to drier and upper layers of dense forests (Vergara-Torres et al., 2010; Ruiz-Cordova et al. 2014; Flores-Palacios et al. 2015a; Flores-Palacios et al. 2015b). In landscapes with high tree densities, as in dense forests or reforestation systems, the high genetic drift promoted by a stronger resistance for wind dispersal (Barrett \& Kohn 1991), in addition to the reduced fitness of T. recurvata, led to small, transient and isolated populations with low genetic diversities. The drastic reductions in tree densities induced by human-modifications in natural landscapes may have led to a partial loss of resistance for seed dispersal by wind and increased the conditions for the optimal development of $T$. recurvata. This dynamic may explain the massive abundance of $T$. recurvata individuals at lower tree densities. The high proliferation of $T$. recurvata at low tree densities suggests that humaninduced deforestation plays an essential role in driving the rapid spread of opportunistic plants within landscapes that once limited their proliferation and gene dispersal. As pointed out by our sensitivity tests, the combined effects of massive regional seed rains and high rates of germination and seed capturing may explain the successful invasion of $T$. recurvata in human-transformed landscapes, besides its transitory and relatively high genetic structure (e.g., Caldiz \& Fernández, 1995; Flores-Palacios et al., 2014).

\section{Conclusion}

Opportunistic species provide an excellent opportunity to examine the process of successful colonization in novel environments (van Etten at al. 2017). Our results showed that the 
effects of high spatial genetic structure, reduced local genetic diversity, and inbreeding, due to selfing and clonal growth of weeds (e.g., Heywood 1991; Barrett 2015; Razanajatovo et al. 2016), can be overwhelmed by a rapid spread across optimal open landscapes. We also demonstrate here that the reduced tree densities, commonly found in human-transformed landscapes, may have created suitable conditions for the rapid spread of $T$. recurvata into areas that might be previously limiting seed dispersal and establishment. Therefore, the reforestation of landscapes dominated by weeds with similar requirements could be an effective strategy to control their spreading.

\section{ACKNOWLEDGMENTS}

This research is part of the first author's thesis (Chaves 2019) and was supported by resources supplied by the Center for Scientific Computing (NCC/GridUNESP) from São Paulo State University (UNESP). We thank A. Santos for computing support. We thank S. Kakazu and M. Bacc for genotyping procedures. C.J.N.C received Ph.D. scholarships from CAPES and FAPESP (2016/04396-4; BEPE 2017/01559-2); B.S.S.L was funded by FAPESP (2014/08087-0); D.R.R. and C.P.S. were funded by Conselho Nacional de Desenvolvimento Científico e Tecnológico (CNPq 471756/ 2013-0 and 300819/2016-1, respectively).

\section{DATA AVAILABILITY}

The microsatellite data generated in this study, as well as all scripts used in the simulations, are stored at FigShare repository [doi:10.6084/m9.figshare.12797846].

\section{AUTHOR CONTRIBUTIONS}

CJNC conceived and designed the research, designed the IBM, proceeded and analyzed the empirical and simulated data, and wrote the draft manuscript. BSSL contributed to the simulated analysis and discussion. BSSL and CPS contributed to empirical study and discussion. DRR contributed to the empirical material collection and design. UB contributed to the model conception. All authors contributed to manuscript revision, read, and approved the submitted version.

\section{REFERENCES}

Aguilar-Rodríguez, S., Terrazas, T., Huidobro-Salas, M. E., \& Aguirre-León, E. (2016). Anatomical and histochemical bark changes due to growth of Tillandsia recurvata (ball moss). Botanical Sciences, 94(3), 551-562. doi:10.17129/botsci.531 
Airoldi, L., \& Bulleri, F. (2011). Anthropogenic disturbance can determine the magnitude of opportunistic species responses on marine urban infrastructures. PLoS ONE, 6(8). doi:10.1371/journal.pone.0022985

Atwater, D. Z., Fletcher, R. A., Dickinson, C. C., Paterson, A. H., \& Barney, J. N. (2018). Evidence for fine-scale habitat specialisation in an invasive weed. Journal of Plant Ecology, 11(2), 189-199. doi:10.1093/jpe/rtw124

Bailleul, D., Stoeckel, S., \& Arnaud-Haond, S. (2016). RClone: a package to identify MultiLocus Clonal Lineages and handle clonal data sets in r. Methods in Ecology and Evolution, 7(8), 966-970. doi:10.1111/2041-210X.12550

Baker, H. G. (1955). Self-Compatibility and Establishment After "Long-Distance" Dispersal. Evolution, 9(3), 347. doi:10.2307/2405656

Baker, H. G. (1974). The Evolution of Weeds. Annual Review of Ecology and Systematics, 5, 124. doi:10.2307/2096877

Barluenga, M., Austerlitz, F., Elzinga, J. A., Teixeira, S., Goudet, J., \& Bernasconi, G. (2011). Fine-scale spatial genetic structure and gene dispersal in Silene latifolia. Heredity, 106(1), 13-24. doi:10.1038/hdy.2010.38

Barrett, S. C. H. (2013). Evolution of Mating Systems: Outcrossing versus Selfing. In J. B. Losos (Ed.), The Princeton Guide to Evolution (pp. 356-362). New Jersey: Princeton University Press.

Barrett, S. C. H. (2015). Influences of clonality on plant sexual reproduction. Proceedings of the National Academy of Sciences, 112(29), 8859-8866. doi:10.1073/pnas.1501712112

Barrett, S. C. H., \& Harder, L. D. (2017). The Ecology of Mating and Its Evolutionary Consequences in Seed Plants. Annual Review of Ecology, Evolution, and Systematics, 48(1), annurev-ecolsys-110316-023021. doi:10.1146/annurev-ecolsys-110316-023021

Barrett, S. C. H., \& Kohn, L. M. (1991). Genetic and evolutionary conse- quences of small population size in plants: implications for conservation. In D. A. Falk \& K. E. Holsinge (Eds.), Genetics and Conservation of Rare Plants (pp. 3-30). Oxford: Oxford University Press.

Barrett, S. C. H., Arunkumar, R., \& Wright, S. I. (2014). The demography and population genomics of evolutionary transitions to self-fertilization in plants. Philosophical Transactions of the Royal Society B: Biological Sciences, 369(1648), 20130344. 
Bartoli, C. G., Beltrano, J., Fernández, L. V., \& Caldíz, D. O. (1993). Control of the Epiphytic Weeds Tillandsia-Recurvata and Tillandsia-Aeranthos with Different Herbicides. Forest Ecology and Management, 59, 289-294.

Belinchón, R., Harrison, P. J., Mair, L., Várkonyi, G., \& Snäll, T. (2017). Local epiphyte establishment and future metapopulation dynamics in landscapes with different spatiotemporal properties. Ecology, 98(3), 741-750. doi:10.1002/ecy.1686

Benzing, D. H. (2000). Bromeliaceae: profile of an adaptive radiation. Cambridge: Cambridge University Press.

Benzing, D. H. (2012). Air Plants: epiphytes and aerial gardens. New York, NY: Cornell University Press.

Birge, W. I. (1911). The anatomy and some biological aspects of the "ball moss", tillandsia recurvata L. Bulletin of The University of Texas, 194(20).

Booth, B. D., \& Swanton, C. J. (2002). Assembly theory applied to weed communities 50th Anniversary - Invited Article Assembly theory applied to weed communities. Weed Science, 50(3), 2-13. doi:10.1614/0043-1745(2002)050

Brook, B. W., Sodhl, N. S., \& Ng, P. K. L. (2003). Catastrophic extinctions follow deforestation in Singapore. Nature, 424(6947), 420-423.

Buckley, Y. M. et al. 2007. Disturbance, invasion and re-invasion: managing the weed-shaped hole in disturbed ecosystems. - Ecol. Lett. 10: 809-817.

Burns, K. C. (2007). Network properties of an epiphyte metacommunity. Journal of Ecology, 95(5), 1142-1151.

Caldiz, D. O., \& Fernández, L. V. (1995). The role of the epiphytic weeds Tillandsia recurvata and T. aëranthos in native rural and urban forest. International Journal of Ecology and Environmental Sciences, 21, 177-197.

Ceballos, G., Garcia, A., Pringle, R. M., Ceballos, G., Ehrlich, P. R., Barnosky, A. D., ... Palmer, T. M. (2015). Accelerated modern human - induced species losses : Entering the sixth mass extinction Accelerated modern human - induced species losses: Entering the sixth mass extinction. Science Advances, 1(June), 1-6. doi:10.1126/sciadv.1400253

Charbonneau, A., Tack, D., Lale, A., Goldston, J., Caple, M., Conner, E., ... Conner, J. K. (2018). Weed evolution: Genetic differentiation among wild, weedy, and crop radish. Evolutionary Applications, (August), 1-11. doi:10.1111/eva.12699 
Charney, N., \& Record, S. (2012). Vegetarian: jost diversity measures for community data.

Chaves, C. J. N. (2019) Ecologia de Metapopulações e Metacomunidades de bromélias atmosféricas. [thesis]. (Rio Claro/Brazil]: Universidade Estadual Paulista (UNESP). Available at: https://repositorio.unesp.br/handle/11449/181033 (Acessed April 27, 2020).

Chaves, C. J. N., Dyonisio, J. C. J. C., \& Rossatto, D. R. D. R. (2016). Host trait combinations drive abundance and canopy distribution of atmospheric bromeliad assemblages. AoB Plants, 8(October 2015), plw010. doi:10.1093/aobpla/plw010

Chaves, C. J. N. et al. 2018. Transferability of nuclear microsatellite markers to the atmospheric bromeliads Tillandsia recurvata and T. aeranthos (Bromeliaceae). - Brazilian J. Bot. in press.

Chaves, C. J., \& Rossatto, D. R. (2020). Unravelling intricate interactions among atmospheric bromeliads with highly overlapping niches in seasonal systems. Plant Biology, 22(2), 243251.

Chazdon, R. L. (2008). Beyond deforestation: Restoring degraded lands. Science, 320, 1458-1460.

Chilpa-Galván, N., Márquez-Guzmán, J., Zotz, G., Echevarría-Machado, I., Andrade, J. L., Espadas-Manrique, C., \& Reyes-García, C. (2018). Seed traits favouring dispersal and establishment of six epiphytic Tillandsia (Bromeliaceae) species. Seed Science Research, 111. doi:10.1017/S0960258518000247

Chung, M. Y. et al. 2018. Fine-scale genetic structure in populations of the spring ephemeral herb Megaleranthis saniculifolia (Ranunculaceae). - Flora Morphol. Distrib. Funct. Ecol. Plants 240: $16-24$.

Claver, F. K., Alaniz, J. R., \& Caldíz, D. O. (1983). Tillandsia spp.: Epiphytic weeds of trees and bushes. Forest Ecology and Management, 6(4), 367-372. doi:10.1016/0378-1127(83)900440

Côrtes, M. C. et al. 2013. Low plant density enhances gene dispersal in the Amazonian understory herb Heliconia acuminata. - Mol. Ecol. 22: 5716-5729.

Counsens, R., \& Mortimer, M. (1995). Dynamics of Weed Populations. New York: Cambridge University Press.

Cousens, R. et al. 2008. Dispersal in Plants. A population perspective. - Oxford University Press. 
600

601

602

603

604

605

606

607

608

609

610

611

612

613

614

615

616

617

618

619

620

621

Csilléry, K., Blum, M. G. B., Gaggiotti, O. E., \& François, O. (2010). Approximate Bayesian Computation (ABC) in practice. Trends in Ecology and Evolution, 25(7), 410-418. doi:10.1016/j.tree.2010.04.001

Cushman, S. A., Shirk, A., \& Landguth, E. L. (2012). Separating the effects of habitat area, fragmentation and matrix resistance on genetic differentiation in complex landscapes. Landscape Ecology, 27(3), 369-380. doi:10.1007/s10980-011-9693-0

de Bona, S. et al. 2019. Spatio-temporal dynamics of density-dependent dispersal during a population colonisation. - Ecol. Lett. 22: 634-644.

de Wet, J. M. J., \& Harlan, J. R. (1975). Weeds and Domesticates: Evolution in the man-made habitat. Economic Botany, 29(2), 99-108. doi:10.1007/BF02863309

Dray, S., \& Dufour, A.-B. (2007). The ade4 Package: Implementing the Duality Diagram for Ecologists. Journal of Statistical Software, 22(4). doi:10.18637/jss.v022.i04

Edwards, A. W. F. (1971) Distance between populations on the basis of gene frequencies. Biometrics, 27, 873-881.

Einzmann, H. J. R. and Zotz, G. 2017. "No signs of saturation”: long-term dynamics of vascular epiphyte communities in a human-modified landscape. - Biodivers. Conserv. 26: 1393-1410.

Epps, C. W., \& Keyghobadi, N. (2015). Landscape genetics in a changing world: Disentangling historical and contemporary influences and inferring change. Molecular Ecology, 24(24), 6021-6040. doi:10.1111/mec.13454

Flores-Palacios, A., Barbosa-Duchateau, C. L., Valencia-Díaz, S., Capistrán-Barradas, A., \& García-Franco, J. G. (2014). Direct and indirect effects of Tillandsia recurvata on Prosopis laevigata in the Chihuahua desert scrubland of San Luis Potosi, Mexico. Journal of Arid Environments, 104, 88-95. doi:10.1016/j.jaridenv.2014.02.010

Flores-Palacios, A., García-Franco, J. G., \& Capistrán-Barradas, A. (2015)a. Biomass, phorophyte specificity and distribution of Tillandsia recurvata in a tropical semi-desert environment (Chihuahuan Desert, Mexico). Plant Ecology and Evolution, 148(1), 68-75.

Flores-Palacios, A., Bustamante-Molina, A. B., Corona-López, A. M., \& Valencia-Díaz, S. (2015)b. Seed number, germination and longevity in wild dry forest Tillandsia species of horticultural value. Scientia Horticulturae 187: 72-79. 
Flores-palacios, A., \& García-Franco, J. G. (2006). The relationship between tree size and epiphyte species richness: testing four different hypotheses. Journal of Biogeography, 33(2), $323-330$.

Foster, M. D. (1945). Blueprint of the jungle as depicted by the altitude of growth of the Bromeliadswith notes on the culture of certain tropical epiphytes. Bulletin of New York Botanical Garden, 46, 9-16.

GBIF Secretariat (2017). GBIF Backbone Taxonomy. Checklist dataset https://doi.org/10.15468/39omei accessed via GBIF.org on 2018-10-23.

Grimm, V., \& Railsback, S. F. (2005). Individual-based Modelling and Ecology. New Jersey: Princeton University Press.

Grimm, V., Berger, U., Bastiansen, F., Eliassen, S., Ginot, V., Giske, J., ... DeAngelis, D. L. (2006). A standard protocol for describing individual-based and agent-based models. Ecological Modelling, 198(1-2), 115-126. doi:10.1016/j.ecolmodel.2006.04.023

Grimm, V., Berger, U., DeAngelis, D. L., Polhill, J. G., Giske, J., \& Railsback, S. F. (2010). The ODD protocol: A review and first update. Ecological Modelling, 221(23), 2760-2768. doi:10.1016/j.ecolmodel.2010.08.019

Hamrick, J. L. and Trapnell, D. W. 2011. Using population genetic analyses to understand seed dispersal patterns. - Acta Oecologica 37: 641-649.

Harrison, S., Ross, S. J., Lawton, J. H., Harrison, S., Ross, S. J., \& Lawtont, J. H. (1992). Beta Diversity on Geographic Gradients in Britain. Journal of Animal Ecology, 61(1), 151-158.

Hewitt, G. M. (1996). Some genetic consequences of ice ages, and their role in speciation. Biological Journal of the Linnaean Society, 58(July), 247-276. Retrieved from papers3://publication/uuid/B9DB7D5E-D6AE-404C-BFFC-9F8133453294

Heywood, J. S. (1991). Spatial analysis of genetic variation in plant populations. Annual Review of Ecology and Systematics, 22, 335-355.

Hooper, E., Condit, R., \& Legendre, P. (2002). Responses of 20 native tree species to reforestation strategies for abandoned farmland in Panama. Ecological Applications, 12(6), $1626-1641$. 
Jackson, N. D., \& Fahrig, L. (2016). Habitat amount, not habitat configuration, best predicts population genetic structure in fragmented landscapes. Landscape Ecology, 31(5), 951-968. doi:10.1007/s10980-015-0313-2

Johnston, A. S. A., Hodson, M. E., Thorbek, P., Alvarez, T., \& Sibly, R. M. (2014). An energy budget agent-based model of earthworm populations and its application to study the effects of pesticides. Ecological Modelling, 280, 5-17.

Jost, L. (2007). Partitioning Diversity into Independent Alpha and Beta Components. Ecology, 88(10), 2427-2439. doi:10.1890/07-1861.1

Kamvar, Z. N., Tabima, J. F., \& Grünwald, N. J. (2014). Poppr: an R package for genetic analysis of populations with clonal, partially clonal, and/or sexual reproduction. PeerJ. doi:10.7717/peerj.281

Keenan, K., Mcginnity, P., Cross, T. F., Crozier, W. W., \& Prodöhl, P. A. (2013). DiveRsity: An $\mathrm{R}$ package for the estimation and exploration of population genetics parameters and their associated errors. Methods in Ecology and Evolution. doi:10.1111/2041-210X.12067

Klimeš, L., Klimešová, J., Hendriks, R., \& van Groenendael, J. (1997). Clonal plant architecture: a comparative analysis of form and function. In H. De Kroon \& J. M. Van Groenendael (Eds.), The ecology and evolution of clonal plants (pp. 1-29). Backhuys.

Kooijman, B., \& Kooijman, S. A. L. M. (2010). Dynamic energy budget theory for metabolic organisation. Cambridge university press.

Kronholm, I., Loudet, O., \& de Meaux, J. (2010). Influence of mutation rate on estimators of genetic differentiation - lessons from Arabidopsis thaliana. BMC Genet, 11, 33. doi:10.1186/1471-2156-11-33

Kuester, A., Conner, J. K., Culley, T., \& Baucom, R. S. (2014). How weeds emerge: A taxonomic and trait-based examination using United States data. New Phytologist, 202(3), 1055-1068. doi:10.1111/nph.12698

Li, J., \& Dong, M. (2009). Fine-scale clonal structure and diversity of invasive plant Mikania micrantha H.B.K. and its plant parasite Cuscuta campestris Yunker. Biological Invasions, 11(3), 687-695. doi:10.1007/s10530-008-9283-5

Loiselle, B. A., Sork, V. L., Nason, J., \& Graham, C. (1995). Spatial Genetic Structure of a Tropical Understory Shrub, Psychotria officinalis (Rubiaceae). American Journal of Botany, 82(11), 1420-1425. 
Loreau, M. et al. 2013. Unifying sources and sinks in ecology and Earth sciences. - Biol. Rev. 88: 365-379.

Martins, S. E. (2009). Flora fanerogâmica do estado de São Paulo. FAPESP: Instituto de Botânica.

McWilliams, E. (1992). Chronology of the natural range expansion of Tillandsia recurvata (Bromeliaceae) in Texas. Contributions to Botany (Vol. 15).

Nathan, R., Horn, H. S., Chave, J., \& Levin, S. A. (2002). Mechanistic models for tree seed dispersal by wind in dense forests and open landscapes. In Seed Dispersal and frugivoryEcologie, Evolution, Conservation (pp. 69-82). doi:10.1079/9780851995250.0069

Nei, M. (1972) Genetic distances between populations. The American Naturalist, 106, 283-292.

Orozco-Ibarrola, O. A., Flores-Hernández, P. S., Victoriano-Romero, E., Corona-López, A. M., \& Flores-Palacios, A. (2015). Are breeding system and florivory associated with the abundance of Tillandsia species (Bromeliaceae)? Botanical Journal of the Linnean Society, 177(1), 5065. doi:10.1111/boj.12225

Pannell, J. R., \& Barrett, S. C. H. (1998). Baker's law revisited: Reproductive assurance in a metapopulation. Evolution, 52(3), 657-668. doi:10.2307/2411261

Paradis, E. (2010). pegas: an R package for population genetics with an integrated-modular approach. Bioinformatics 26, 419-420.

Pettengill, J. B., Briscoe Runquist, R. D., \& Moeller, D. A. (2016). Mating system divergence affects the distribution of sequence diversity within and among populations of recently diverged subspecies of Clarkia xantiana (Onagraceae). American Journal of Botany, 103(1), 99-109. doi:10.3732/ajb.1500147

Pyšek, P., \& Hulme, P. E. (2005). Spatio-temporal dynamics of plant invasions: Linking pattern to process. Ecoscience, 12(3), 302-315.

Razanajatovo, M., Maurel, N., Dawson, W., Essl, F., Kreft, H., Pergl, J., ... Van Kleunen, M. (2016). Plants capable of selfing are more likely to become naturalized. Nature Communications, 7, 13313. doi:10.1038/ncomms 13313

Ren, M. X., Cafasso, D., Cozzolino, S., \& Pinheiro, F. (2017). Extensive genetic differentiation at a small geographical scale: Reduced seed dispersal in a narrow endemic marsh orchid, Anacamptis robusta. Botanical Journal of the Linnean Society, 183(3), 429-438. doi:10.1093/botlinnean/bow017 
Reynolds, J. B., B. S. Weir, and C. C. Cockerham. (1983) Estimation of the coancestry coefficient: basis for a short-term genetic distance. Genetics, 105, 767-779.

Richardson, D. M., Pysek, P., Rejmanek, M., Barbour, M. G., Panetta, F. D., \& West, C. J. (2008). Naturalization and Invasion of Alien Plants: Concepts and Definitions. Diversity and Distributions, 6, 93-107.

Rodger, J. G., Van Kleunen, M., \& Johnson, S. D. (2013). Pollinators, mates and Allee effects: The importance of self-pollination for fecundity in an invasive lily. Functional Ecology, 27(4), 1023-1033. doi:10.1111/1365-2435.12093

Santos, L. S. dos et al. 2014. Generalized Allee effect model. - Theory Biosci. 133: 117-124.

Slatkin, M. (1995) A measure of population subdivision based on microsatellite allele frequencies. Genetics, 139, 457-462.

Smith, A. K., Martin, C. E., \& Lüttge, U. (1989). Gas exchange and water vapor uptake in the atmospheric CAM bromeliad Tillandsia recurvata L.: the influence of trichomes. Botanica Acta, 102, 80-84.

Smith, L. B., \& Downs, R. J. (1977). Tillandsioideae (Bromeliaceae). In Flora Neotropica (pp. 661-1178).

Snäll, T., Ehrlén, J., \& Rydin, H. (2005). Colonization-Extinction Dynamics of an Epiphyte Metapopulation in a Dynamic Landscape. Ecology, 86(1), 106-115.

Sibly, R. M., Grimm, V., Martin, B. T., Johnston, A. S. A., Kulakowska, K., Topping, C. J., ... Deangelis, D. L. (2013). Representing the acquisition and use of energy by individuals in agent-based models of animal populations. Methods in Ecology and Evolution, 4(2), 151-161.

Soltis, D. E., Gilmartin, A. J., Rieseberg, L., \& Gardner, S. (1987). Genetic Variation in the Epiphytes Tillandsia ionantha and T. recurvata (Bromeliaceae). American Journal of Botany, 74(4), 531-537.

Southwood, T., \& Kennedy, C. (1983). Trees as islands. Oikos, 41(3), 359-371. doi:10.2307/3544094

Spruch, L. et al. 2019. Modeling community assembly on growing habitat "islands": a case study on trees and their vascular epiphyte communities. - Theor. Ecol.: 1-17. 
Torres, E., Riofrío, M.-L., \& Iriondo, J. M. (2018). Complex fine-scale spatial genetic structure in Epidendrum rhopalostele: an epiphytic orchid. Heredity. doi:10.1038/s41437-018-0139-1

Trapnell, D. W., Hamrick, J. L., \& Nason, J. D. (2004). Three-dimensional fine-scale genetic structure of the neotropical epiphytic orchid, Laelia rubescens. Molecular Ecology, 13, 11111118.

van der Vaart, E., Johnston, A. S. A., \& Sibly, R. M. (2016). Predicting how many animals will be where: How to build, calibrate and evaluate individual-based models. Ecological Modelling, 326, 113-123.

Vergara-Torres, C. A. et al. 2010. Host preference and host limitation of vascular epiphytes in a tropical dry forest of central Mexico. - J. Trop. Ecol. 26: 563-570.

Vallejo-Marín, M., Dorken, M. E., \& Barrett, S. C. H. (2010). The Ecological and Evolutionary Consequences of Clonality for Plant Mating. Annual Review of Ecology, Evolution, and Systematics, 41(1), 193-213. doi:10.1146/annurev.ecolsys.110308.120258

van Etten, M. L., Conner, J. K., Chang, S. M., \& Baucom, R. S. (2017). Not all weeds are created equal: A database approach uncovers differences in the sexual system of native and introduced weeds. Ecology and Evolution, 7(8), 2636-2642. doi:10.1002/ece3.2820

van Kleunen, M., Fischer, M., \& Johnson, S. D. (2007). Reproductive assurance through selffertilization does not vary with population size in the alien invasive plant Datura stramonium. Oikos, 116(8), 1400-1412. doi:10.1111/j.0030-1299.2007.16004.x

van Kleunen, M. et al. 2018. The Ecology and Evolution of Alien Plants. - Annu. Rev. Ecol. Evol. Syst. 49: annurev-ecolsys-110617-062654.

Vekemans, X., \& Hardy, O. J. (2004). New insights from fine-scale spatial genetic structure analyses in plant populations. Molecular Ecology, 13(4), 921-935. doi:10.1046/j.1365294X.2004.02076.x

Vergara-Torres, C. A., Pacheco-Álvarez, M. C., \& Flores-Palacios, A. (2010). Host preference and host limitation of vascular epiphytes in a tropical dry forest of central Mexico. Journal of Tropical Ecology, 26(6), 563-570. doi:10.1017/S0266467410000349

Victoriano-Romero, E., Valencia-Díaz, A., Toledo-Hernández, V. H., \& Flores-Palacios, A. (2017). Dispersal limitation of Tillandsia species correlates with rain and host structure in a central Mexican tropical dry forest. PLoS ONE, 12(2): e0171614. 
Ward, S. (2006). Genetic analysis of invasive plant populations at different spatial scales. Biological Invasions, 8(3), 541-552. doi:10.1007/s10530-005-6443-8

Wilcove, D. S. (1985). Nest Predation in Forest Tracts and the Decline of Migratory Songbirds. Ecology, 66(4), 1211-1214.

Wilensky, U. (1999). NetLogo. Evanston: Northwestern University, Center for Connected Learning and Computer-Based Modeling. 3 